\title{
Trigeminal Neuralgia Secondary to Compression by a Microsurgical Aneurysm Clip
}

\author{
Kutluay ULUC, Daniel MUNGER, Ahmed RASLAN, Aclan DOGAN \\ Oregon Health \& Science University, Department of Neurological Surgery, Portland, OR, USA
}

Corresponding author: Aclan DOGAN dogana@ohsu.edu

12

To watch the surgical videoclip, please visit http://turkishneurosurgery.org.tr/uploads/jtn-33334-video.mp4

\section{ABSTRACT}

Microvascular decompression (MVD) is a common surgical technique used for treatment of trigeminal neuralgia (TN) caused by direct vascular compression of the nerve at the brainstem entry zone (BEZ). Here we report a case of a patient (status postcraniotomy for microsurgical clip obliteration of a ruptured mid-basilar artery aneurysm) who developed right-sided TN 6 years after the procedure. During MVD surgery the clip head was found to be compressing the trigeminal nerve at the BEZ, causing Type $1 \mathrm{TN}$ in V3 distribution. This is consistent with the commonly held theory that a pulsatile stimulus is needed to cause TN. To our knowledge there are no previous reports in the literature of an instrument causing TN.

KEYWORDS: Trigeminal neuralgia, Microsurgical clip, Microvascular decompression

\section{INTRODUCTION}

$\mathrm{T}$ Trigeminal neuralgia (TN) is a debilitating condition with a prevalence of $4-13$ per 100,000 each year, and usually presents between the fourth and seventh decades (1, 8,12 ). Approximately $10-25 \%$ of patients do not respond or become refractory to medical therapy, which constitutes firstline treatment (15).

Vascular compression is the most common cause of TN (10). The myelin sheath of the trigeminal nerve has a transitional zone of central myelin to peripheral nerve myelin at the brainstem entry zone (BEZ). This transition zone is where the nerve is most vulnerable to injury (3). Previous authors have suggested that the pulsatile nature of the compression located at the BEZ plays a significant role in the etiology of TN (10). Microvascular decompression (MVD) has high success rates in patients with TN secondary to vascular compression. Approximately $80 \%$ of MVD patients experience immediate pain relief, with $75 \%$ and $64 \%$ maintaining relief after 1 year and 10 years, respectively (2).

\section{CASE REPORT}

A57-year-old female presented with subarachnoid hemorrhage secondary to mid-basilar artery aneurysm rupture (Figure 1A). Initial angiography was negative (Figure 1B), however repeat angiography 4 days after presentation revealed a 4 $\mathrm{mm}$ saccular aneurysm arising from the posterior distal third of the basilar artery and projecting towards the right (Figure 1C). At this point the patient was in the vasospasm period, therefore therapy was delayed until post-bleed day 14. A diagnostic cerebral angiogram was repeated pre-operatively (Figure 1D) followed by successful microsurgical clip ligation of the aneurysm via a transpetrosal transcrusal approach (Figure 1E and Video 1). Post-operatively the patient's hearing was intact. The patient made a good recovery, which was only
Kutluay ULUC (1) : 0000-0002-5739-9468 Daniel MUNGER (1) : 0000-0002-4001-527X
Ahmed RASLAN (1) : 0000-0002-8421-7105

Aclan DOGAN (D) : 0000-0002-4113-1619 

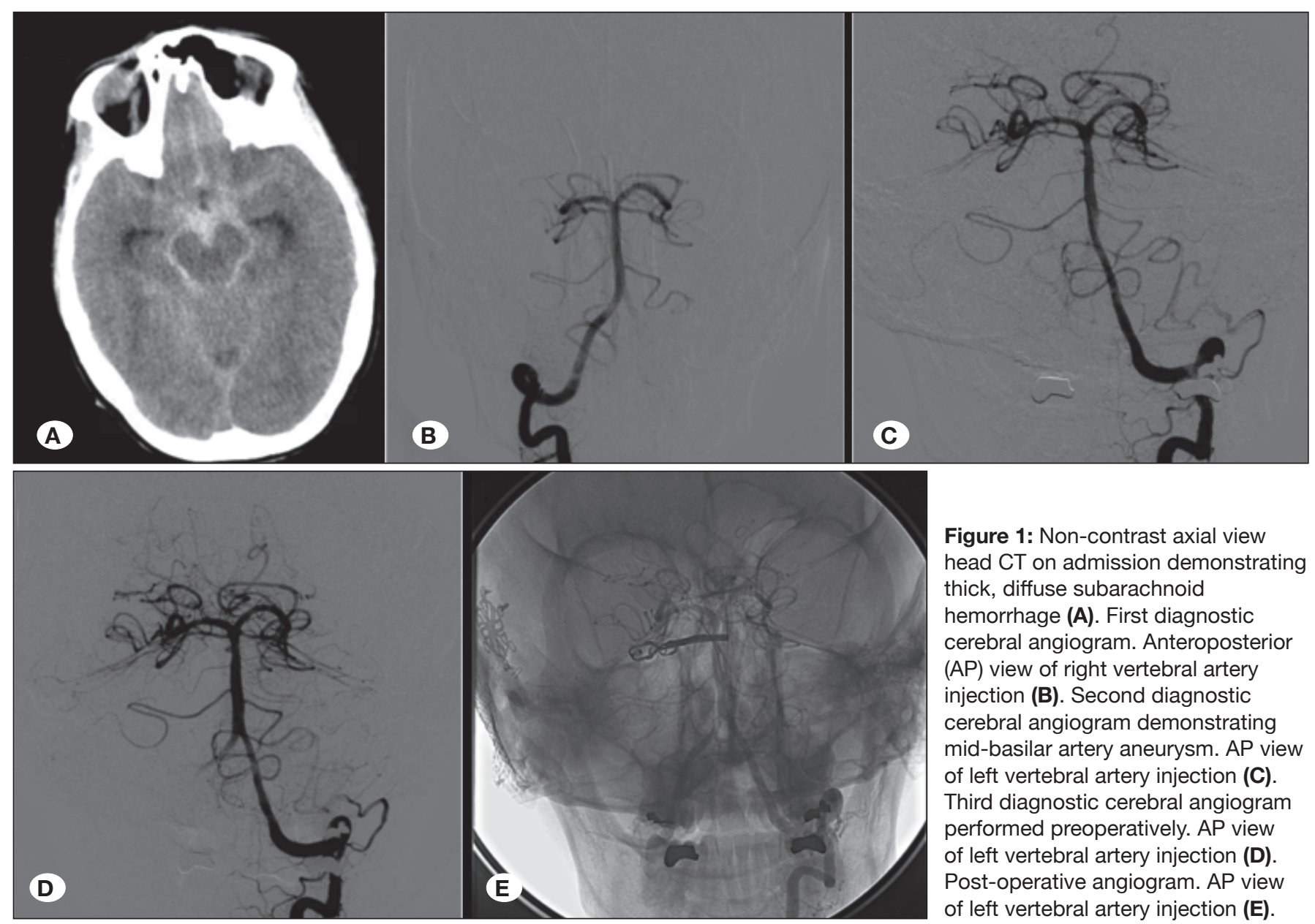

Figure 1: Non-contrast axial view head CT on admission demonstrating thick, diffuse subarachnoid hemorrhage (A). First diagnostic cerebral angiogram. Anteroposterior (AP) view of right vertebral artery injection (B). Second diagnostic cerebral angiogram demonstrating mid-basilar artery aneurysm. AP view of left vertebral artery injection (C). Third diagnostic cerebral angiogram performed preoperatively. AP view of left vertebral artery injection (D). Post-operative angiogram. AP view of left vertebral artery injection (E).

complicated by cerebrospinal fluid leak (CSF) leak 6 months after surgery for which a lumboperitoneal shunt was placed and the wound was revised with use of abdominal fat grafting.

Six years after microsurgical clipping the patient presented with intermittent shooting, electric pain characteristic of TN type 1 (TN1) in the right mandibular (V3) distribution. Magnetic resonance imaging (MRI) evaluation of the trigeminal nerve was limited due to artifact from the microsurgical clip and computed tomography (CT) did not provide sufficiently detailed anatomy (Figure 2A, B). The patient underwent rightsided radiofrequency gangliolysis of the trigeminal nerve; two lesions were placed at 80 degrees for 90 seconds. Symptom resolution was achieved for two and a half years.

However, despite both radiofrequency ablation and maximal medical therapies TN1 symptoms recurred. Ten years after initial surgery and 4 years after radiofrequency gangliolysis the patient underwent microvascular decompression (MVD). Intraoperatively, the clip head was found to be compressing the right trigeminal nerve at the BEZ. The clip head was retracted away from the nerve and Telfa pledgets were placed in between. Following MVD the patient's symptomatology completely resolved. At last follow up visit 5 months postoperatively her TN pain had fully subsided. The subject signed the relevant institutional consent to publish the case report presented above.

\section{DISCUSSION}

The etiology of TN is variable including; vascular compression, multiple sclerosis, tumor compression, infiltration by neoplasm or amyloid, trauma, postherpetic, familial, postinfarction or secondary to angiomas of the pons or medulla $(1,6,10)$. Demyelinization has a critical role in the development of TN, however, TN may also be related to other etiologies $(1,4,11)$. Radiosurgery or percutaneous rhizotomy by various techniques (e.g. glycerol, balloon, and radiofrequency) have been described as successful treatments $(1,5,7,14)$. Carbamazepine is the first-line medical therapy. Baclofen, gabapentin, lamotrigine, oxcarbazepine, phenytoin and pimozide are other medication options $(1,3,4)$. Although many TN cases are idiopathic, several studies have demonstrated that $80-90 \%$ of such idiopathic cases are due to vascular compression $(9,13)$. MVD has high success rates in TN secondary to vascular compression $(1,2,4)$.

This is the first case report of a microsurgical clip as the cause of TN. The patient underwent clip occlusion of a ruptured midbasilar artery aneurysm via transpetrosal transcrusal approach 


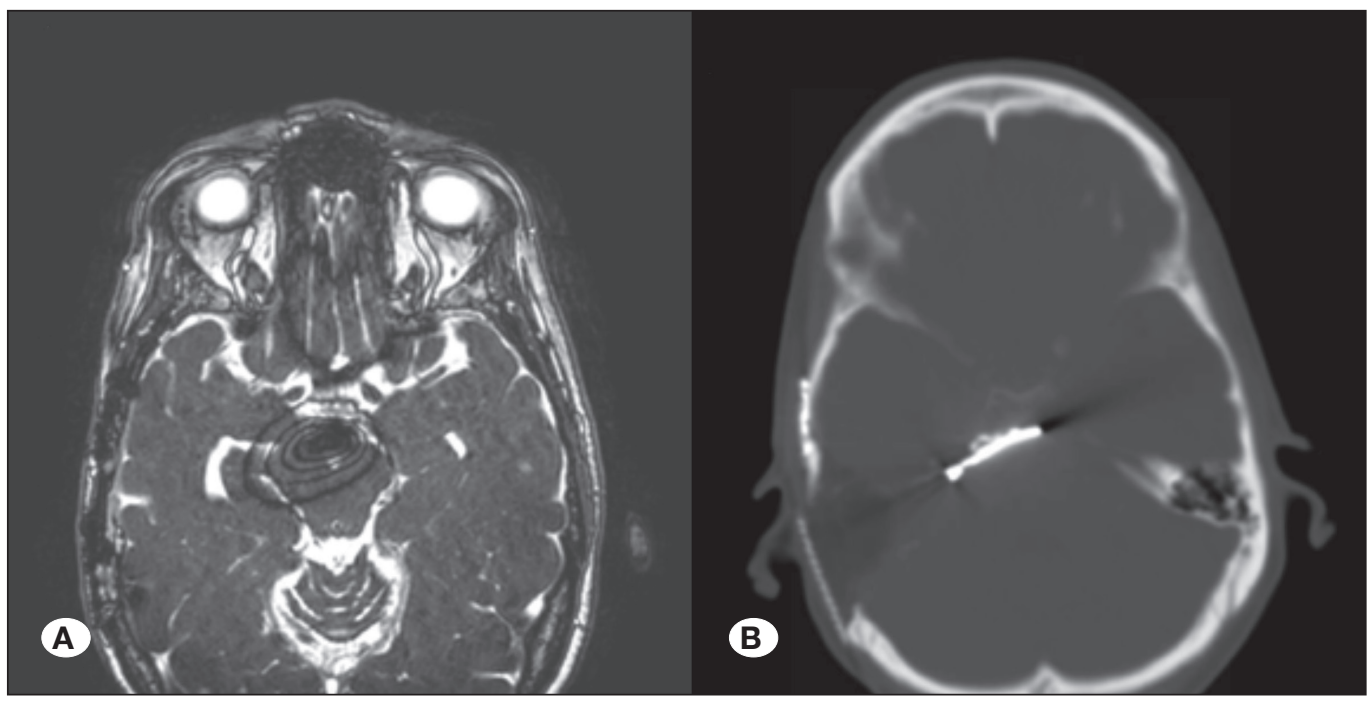

Figure 2: Post-operative MRI showing the artifact from clip (A) and post-operative CTA head with the clip artifact (B). and developed TN 6 years later. The delayed interval between clip placement and development of $\mathrm{TN}$ is consistent with the finding that symptoms generally occur following a prolonged stimulus. The patient underwent retrosigmoid craniectomy for MVD where it was found that the compression of the trigeminal nerve at the BEZ was due to the microsurgical clip rather than a vascular structure. We postulate that the microsurgical clip caused TN by simultaneous compression of the BEZ while transmitting basilar artery pulsations.

\section{CONCLUSION}

Direct compression by a device should be considered in the etiology of TN in patients with prior intradural instrumentation. It is likely that the case of TN described here is caused by a combination of clip compression along with translation of basilar artery pulsatility through the clip where it contacts the trigeminal nerve. For this type of compressive lesion, MVD comprises definitive treatment by relieving the $\mathrm{TN}$-inducing stimulus.

\section{DECLARATIONS}

Patient Consent: The patient has consented to the submission of the case report for submission to the journal.

\section{REFERENCES}

1. Araya El, Claudino RF, Piovesan EJ, Chichorro JG: Trigeminal neuralgia: Basic and clinical aspects. Current Neuropharmacology 18:109-119, 2020

2. Barker FG, 2nd, Jannetta PJ, Bissonette DJ, Larkins MV, Jho HD: The long-term outcome of microvascular decompression for trigeminal neuralgia. N Engl J Med 334:1077-1083, 1996

3. Bennetto L, Patel NK, Fuller G: Trigeminal neuralgia and its management. BMJ 334:201-205, 2007

4. Cruccu G, Di Stefano G, Truini A: Trigeminal Neuralgia. New England J Med 383:754-762, 2020
5. Dhople AA, Adams JR, Maggio WW, Naqvi SA, Regine WF, Kwok Y: Long-term outcomes of Gamma Knife radiosurgery for classic trigeminal neuralgia: Implications of treatment and critical review of the literature. Clinical article. J Neurosurg 111:351-358, 2009

6. Eller JL, Raslan AM, Burchiel KJ: Trigeminal neuralgia: Definition and classification. Neurosurg Focus 18:E3, 2005

7. Green TH, Girgis F: Trigeminal neuralgia: Medical management and surgical options. J Pain Palliat Care Pharmacother 33:3233, 2019

8. Katusic S, Beard CM, Bergstralh E, Kurland LT: Incidence and clinical features of trigeminal neuralgia, Rochester, Minnesota, 1945-1984. Ann Neurol 27:89-95, 1990

9. Love S, Coakham HB: Trigeminal neuralgia: Pathology and pathogenesis. Brain 124:2347-2360, 2001

10. Love S, Gradidge T, Coakham HB: Trigeminal neuralgia due to multiple sclerosis: Ultrastructural findings in trigeminal rhizotomy specimens. Neuropathol Appl Neurobiol 27:238244, 2001

11. Maarbjerg S, Di Stefano G, Bendtsen L, Cruccu G: Trigeminal neuralgia - diagnosis and treatment. Cephalalgia 37:648-657, 2017

12. MacDonald BK, Cockerell OC, Sander JW, Shorvon SD: The incidence and lifetime prevalence of neurological disorders in a prospective community-based study in the UK. Brain 123 (Pt 4):665-676, 2000

13. Nurmikko TJ, Eldridge PR: Trigeminal neuralgiapathophysiology, diagnosis and current treatment. $\mathrm{Br} J$ Anaesth 87:117-132, 2001

14. Ong KS, Keng SB: Evaluation of surgical procedures for trigeminal neuralgia. Anesth Prog 50:181-188, 2003

15. Taylor JC, Brauer S, Espir ML: Long-term treatment of trigeminal neuralgia with carbamazepine. Postgrad Med $\mathrm{J}$ 57:16-18, 1981 